\title{
Estabilidade física e química de licores de graviola durante o armazenamento em condições ambientais
}

\author{
Emanuel N. A. de Oliveira ${ }^{1}$, Dyego da C. Santos ${ }^{2}$, Josivanda P. Gomes ${ }^{3}$, \\ Ana P. T. Rocha ${ }^{4}$ \& Esther M. B. de Albuquerque ${ }^{5}$
}

\section{Palavras-chave:}

fruta exótica

bebida alcoólica

estocagem

\begin{abstract}
R E S U M O
Objetivou-se, neste trabalho, desenvolver e avaliar a estabilidade de licores de graviola acondicionados em embalagens de polietileno durante o armazenamento por 240 dias em condições ambientais. Foram elaboradas 5 formulações de licores variando-se as concentrações de polpa (300, 400 e $500 \mathrm{~g})$ e xarope de sacarose $\left(50,60\right.$ e $\left.70{ }^{\circ} \mathrm{Brix}\right)$. As polpas foram maceradas em álcool comercial por 20 dias; em seguida, as misturas foram filtradas, adicionadas de xarope e submetidas a um envelhecimento acelerado em banho-maria, a $60^{\circ} \mathrm{C}$, pelo período de $2 \mathrm{~h}$. Os licores foram acondicionados em embalagens de polietileno de baixa densidade e armazenados em temperatura e umidade relativa médias de $26^{\circ} \mathrm{C}$ e 78\%, respectivamente. No tempo inicial e a cada 60 dias de estocagem, por 240 dias, os licores foram submetidos às análises de teor alcoólico, açúcares totais, sólidos solúveis totais (SST), acidez total titulável (ATT), razão SST/ATT, $\mathrm{pH}$, atividade de água e cor $\left(\mathrm{L}^{*}, \mathrm{a}^{*} \mathrm{e}\right.$ $\left.\mathrm{b}^{\star}\right)$. Observou-se que o armazenamento promoveu aumentos significativos $(\mathrm{p}<0,05)$ nos valores de açúcares totais, SST e cromaticidades $\mathrm{a}^{\star} \mathrm{e} \mathrm{b}^{\star}$. Os parâmetros de teor alcoólico, atividade de água, $\mathrm{pH}$ e luminosidade $\left(\mathrm{L}^{\star}\right)$ foram reduzidos enquanto que a ATT e a razão SST/ATT permaneceram estáveis ao final da estocagem.
\end{abstract}

Key words:

exotic fruit

alcoholic beverage

storage

\section{Physical and chemical stability of soursop liqueurs during storage under ambient conditions}

\begin{abstract}
A B S T R A C T
The objective of this study was to develop and evaluate the stability of soursop liqueurs packaged in polyethylene during storage for 240 days under ambient conditions. Five formulations of liquors were prepared by varying the concentration of pulp (300, 400 and $500 \mathrm{~g}$ ) and sucrose syrup (50,60 and $\left.70^{\circ} \mathrm{Brix}\right)$. The pulps were macerated in alcohol for 20 working days, then the mixtures were filtered, added syrup and subjected to accelerated aging in a water bath at $60{ }^{\circ} \mathrm{C}$ for $2 \mathrm{~h}$. Liqueurs were packed in low density polyethylene and stored at mean temperature and relative humidity of $26^{\circ} \mathrm{C}$ and $78 \%$, respectively. At baseline and every 60 days of storage, for 240 days, the liqueurs were analysed for alcohol content, total sugars, total soluble solids (TSS), titratable acidity (TTA), TSS/TTA ratio, $\mathrm{pH}$, water activity and color $\left(\mathrm{L}^{*}, \mathrm{a}^{*}\right.$ and $\left.\mathrm{b}^{*}\right)$. It was observed that storage promoted significant increases $(p<0.05)$ in the values of total sugars, TSS and $a^{\star}$ and $b^{\star}$ chromaticities. The parameters of alcohol content, water activity, $\mathrm{pH}$ and lightness $\left(\mathrm{L}^{*}\right)$ were reduced, while TSS/TTA ratio remained stable at the end of storage.
\end{abstract}

Protocolo 087-2014 - 19/03/2014 • Aprovado em 24/10/2014 • Publicado em 26/01/2015

${ }^{1}$ IFRN/Campus Pau dos Ferros. Pau dos Ferros, RN. E-mail: emanuelnetoliveira@ig.com.br

${ }^{2}$ UAEA/UFCG. Campina Grande, PB. E-mail: dyego.csantos@gmail.com

${ }^{3}$ UAEA/UFCG. Campina Grande, PB. E-mail: josivanda@gmail.com (Autora correspondente)

${ }^{4}$ UAEA/UFCG. Campina Grande, PB. E-mail: anatrindade@deag.ufcg.edu.br

${ }^{5}$ CCT/UFCG. Campina Grande, PB. E-mail: esther_barros@hotmail.com 


\section{INTRODUÇÃo}

A família Annonaceae compreende cerca de 80 gêneros e 850 espécies que ocorrem nos trópicos. Entre as espécies de interesse é citada a graviola (Annona muricata L.), nativa da América Tropical e das Índias Ocidentais. Ela produz frutos esverdeados com espinhos flexíveis, ovais ou irregulares, com $15-30 \mathrm{~cm}$ de comprimento e pesando cerca de $0,5 \mathrm{~kg}$ (Okigbo \& Obire, 2009). Sua polpa é branca e pegajosa, com sabor e aroma agradáveis. A graviola é cultivada em países tropicais sendo que no Brasil as áreas produtoras estão instaladas principalmente nas regiões litorâneas e semiáridas do Nordeste (Lima et al., 2006).

A alta perecibilidade da graviola e o curto período de conservação após a colheita têm sido responsáveis por altos índices de perdas e por dificuldades no abastecimento de mercados tradicionais e potenciais de consumo da fruta fresca (Lima et al., 2010). Devido a esta fragilidade, a graviola é, em geral, processada na forma de derivados, como polpas, sucos, néctares, geleias e sorvetes. Como mais uma alternativa para estender a vida de prateleira no pós-colheita desta fruta, devese considerar sua utilização no desenvovimento de bebidas, a exemplo de licores que, além de agregar valor à graviola, o processamento de licor também possibilitaria o fornecimento de produtos da fruta a mercados mais distantes das regiões produtoras.

Teixeira et al. (2010) destacaram que a produção de licores constitui uma forma de contornar os problemas relacionados à perecibilidade de frutas. Além disto, é uma alternativa para enfrentar os problemas relacionados ao excesso de produção e baixos preços praticados em alguns períodos. Barros et al. (2008) salientaram que sua produção é uma alternativa interessante para proporcionar aumento da renda familiar haja vista que seu processamento exige tecnologia simples e o produto final é comercializado em temperatura ambiente evitando, assim, custos com a cadeia do frio.

A legislação brasileira define licor como a bebida com graduação alcoólica de 15 a $54 \%$ em volume, a $20{ }^{\circ} \mathrm{C}$, e um percentual de açúcar superior a $30 \mathrm{~g} \mathrm{~L}^{-1}$, elaborado com álcool etílico potável de origem agrícola ou destilado alcoólico simples de origem agrícola ou ainda bebidas alcoólicas, adicionada de extrato ou substâncias de origem vegetal ou animal, substâncias aromatizantes, saborizantes, corantes e outros aditivos permitidos em ato administrativo complementar (Brasil, 2009). É válido ressaltar que o preparo de licores está baseado na maceração alcoólica de frutas ou na destilação de macerados aromáticos com base de frutas. Sua qualidade depende não só da mistura adequada dos ingredientes mas principalmente do processo de preparação (Almeida et al., 2012). Trata-se de um processo simples; no entanto, existem variações no processo, com registro de algumas patentes que visam melhorar a qualidade do produto final (Oliveira \& Santos, 2011).

Uma grande variedade de frutas tem sido utilizada no processamento de licores, a exemplos do abacaxi (Teixeira et al., 2012), tangerina (Almeida et al., 2012), açaí (Oliveira \& Santos, 2011), maracujá (Dias et al., 2011), camu-camu (Vieira et al., 2010), banana (Teixeira et al., 2005), Rubus glaucus (Gómez et al., 2005), acerola (Nogueira \& Venturini Filho, 2005) e murta (Vacca et al., 2003), entre outras; entretanto, são escassos os trabalhos de processamento de licores de graviola (Oliveira et al., 2014), não sendo encontrados na literatura consultada estudos envolvendo o armazenamento de licores de graviola.

Ante o exposto e se considerando a necessidade de processos que agreguem valor e estendam a vida pós-colheita de frutas objetivou-se, com este estudo, desenvolver e avaliar a estabilidade de licores de graviola acondicionados em embalagens de polietileno de baixa densidade durante o armazenamento por 240 dias, em condições ambientais.

\section{Material e Métodos}

Utilizaram-se frutas de graviola (Annona muricata L.) maduras provenientes de pequenos produtores da cidade de Campina Grande, PB, álcool comercial de origem agrícola (vodka) com graduação alcoólica de $39 \%$ (v/v) e xaropes de sacarose nas concentrações de 50, 60 e $70{ }^{\circ}$ Brix elaborados por concentração em fogo brando da solução de açúcar cristal e água. Os frutos da gravioleira foram recepcionados no Laboratório de Armazenamento e Processamento de Produtos Agrícolas (LAPPA) da Univarsidade Federal de Campina Grande (UFCG), onde foram selecionados para remoção de frutas injuriadas e/ou sujeiras provenientes do campo, lavados em água corrente, sanitizados em solução clorada (200 ppm) por 15 min e, na sequência, submetidos a uma segunda lavagem para remoção de cloro residual. Posteriormente, as frutas foram descascadas manualmente com facas de aço inoxidável e separadas a polpa das sementes e cascas, sendo esta polpa homogeneizada em liquidificador doméstico. A polpa foi envasada em sacos de polietileno e acondicionada em freezer $\left(-18^{\circ} \mathrm{C}\right)$ até início da parte experimental.

No processo produtivo dos licores a polpa de graviola foi previamente descongelada sob refrigeração $\left(\sim 4^{\circ} \mathrm{C}\right)$ e, juntamente com o xarope de sacarose e a vodka, utilizada no processamento (Tabela 1). De início, a polpa (300, 400 e $500 \mathrm{~g}$ ) foi submetida, em recipientes de vidro previamente esterilizados e providos de tampa, a uma maceração a frio utilizando-se vodka $(500 \mathrm{~mL})$ pelo período de vinte dias (Carvalho, 2007; Oliveira et al., 2014), com o objetivo de se extrair as substâncias ativas da graviola (Oliveira \& Santos, 2011).

Decorrido o tempo de maceração, os licores foram filtrados em peneira com uma camada fina de algodão para remoção de resíduos provenientes da polpa e adicionados de $400 \mathrm{~mL}$ de xarope de sacarose com 50, 60 e $70^{\circ}$ Brix, conforme Tabela 1 , com a finalidade de promover a elevação dos teores de açúcares e reduzir seus teores alcoólicos. As misturas foram homogeneizadas e submetidas à pasteurização em banho-maria a $60^{\circ} \mathrm{C}$, durante $2 \mathrm{~h}$, nos mesmos potes em que ocorreram as

Tabela 1. Matriz de planejamento utilizada para o processamento dos licores de graviola

\begin{tabular}{cccc}
\hline Formulação & $\begin{array}{c}\text { Polpa } \\
(\mathbf{g})\end{array}$ & $\begin{array}{c}\text { Xarope } \\
\left({ }^{\circ} \text { Brix) }\right.\end{array}$ & $\begin{array}{c}\text { Álcool comercial } \\
(\mathbf{m L})^{* *}\end{array}$ \\
L1 & 300 & 50 & 500 \\
L2 & 500 & 50 & 500 \\
L3 & 300 & 70 & 500 \\
L4 & 500 & 70 & 500 \\
L5 & 400 & 60 & 500 \\
\hline L1.. L5 - Licor de graviola; *Utilizou-se 400 mL de xarope em cada formulação; **Vodka
\end{tabular}


macerações. O aquecimento aplicado na pasteurização dos licores teve, como objetivo, não apenas destruir prováveis micro-organismos patogênicos e deteriorantes, mas também promover o envelhecimento acelerado da bebida; na sequência, os licores foram resfriados em temperatura ambiente, acondicionados em garrafas plásticas de polietileno de baixa densidade providas de tampas enroscadas e armazenados em temperaturas $\left(26^{\circ} \mathrm{C}\right)$ e umidade relativa $(78 \%)$ médias de Campina Grande, PB, pelo período de 240 dias; após o processamento (tempo 0) e a cada 60 dias de armazenamento (tempos 30, 60, 90, 120, 180 e 240 dias) os licores foram submetidos às análises de teor alcoólico de acordo com a AOAC (2010), açúcares totais, sólidos solúveis totais (SST), acidez total titulável em ácido cítrico (ATT) e pH segundo métodos do IAL (2008), relação SST/ATT de acordo com Brasil (1986), atividade de água $\left(\mathrm{a}_{\mathrm{w}}\right)$ em higrômetro AQUA-LAB, modelo CX2, fabricado pela Decagon e cor em espectrofotômetro portátil Hunter Lab Mini Scan XE Plus, modelo 4500 L, obtendo-se os parâmetros $L^{*}, a^{*} e b^{*}$, em que $L^{*}$ define a luminosidade $\left(\mathrm{L}^{\star}=0\right.$ - preto e $\mathrm{L}^{\star}=100$ - branco) e $\mathrm{a}^{\star}$ e $\mathrm{b}^{\star}$ são responsáveis pela cromaticidade $\left(+\mathrm{a}^{\star}\right.$ vermelho $\mathrm{e}-\mathrm{a}^{\star}$ verde; $+\mathrm{b}^{\star}$ amarelo e $-b^{\star}$ azul).

Os experimentos foram conduzidos em delineamento inteiramente casualizado, em esquema fatorial $5 \times 5$, sendo 5 formulações de licor, 5 períodos de armazenamento $(0,60$, 120, 180 e 240 dias), utilizando-se o software Assistat versão 7.5 beta (Silva \& Azevedo, 2008). Os dados foram submetidos à análise de variância (ANOVA) e a comparação de médias foi feita pelo teste de Tukey a 0,05 de probabilidade.

\section{Resultados e Discussão}

No tempo inicial, as bebidas revelaram teores alcoólicos próximos à faixa mínima estabelecida pela legislação, que é de 15 a 54\% v/v (Brasil, 2009), com valores oscilando entre 15,03 (L2) e 16,69\% v/v (L1) (Tabela 2). Apenas os licores elaborados com a menor concentração de polpa (L1 e L3) apresentaram teores alcoólicos superiores a $16 \% \mathrm{v} / \mathrm{v}$, diferindo estatisticamente $(\mathrm{p}<0,05)$ das demais formulações, o que é atribuído à menor diluição do álcool promovido pela adição de polpa. Oliveira \& Santos (2011) elaboraram licor de açaí e reportaram teor alcoólico semelhante, com valor de $16 \%$ v/v. Em contrapartida, Teixeira et al. (2005) encontraram, em licores de banana, teores alcoólicos ligeiramente superiores $(17,80$ a $18,77 \%$ v/v) e Nogueira \& Venturini Filho (2005) relataram, em licores de acerola, valores de 11,9 a $12,8 \% \mathrm{v} / \mathrm{v}$, inferiores, portanto, aos da faixa da legislação (Brasil, 2009).

Todas as formulações de licores de graviola apresentaram reduções significativas $(\mathrm{p}<0,05)$ nos teores alcoólicos durante o armazenamento (Tabela 2). Esses resultados sugerem que a embalagem de polietileno utilizada não ofereceu proteção física eficiente durante a estocagem, isto é, houve trocas gasosas entre os licores e o ambiente favorecendo, deste modo, a volatilização do álcool etílico com o tempo, o que provavelmente, não ocorreria se o armazemento tivesse sido realizado em carrafas de vidro. A partir dos 60 dias de estocagem todas as bebidas apresentaram teores alcoólicos abaixo da faixa estabelecida pela legislação brasileira (Brasil, 2009). Alternativas que poderiam ser utilizadas para minimizar os efeitos da volatilização do álcool com o tempo, seriam o processamento de licores

Tabela 2. Valores médios de teor alcoólico, açúcares totais, sólidos solúveis totais, atividade de água e acidez total titulável de licores de graviola armazenados em condições ambientais

\begin{tabular}{|c|c|c|c|c|c|c|}
\hline \multirow{2}{*}{ Parâmetro } & \multirow{2}{*}{ Formulação } & \multicolumn{5}{|c|}{ Armazenamento (dias) } \\
\hline & & 0 & 60 & 120 & 180 & 240 \\
\hline \multirow{5}{*}{$\begin{array}{c}\text { Teor alcoólico } \\
(\% \mathrm{v} / \mathrm{v})\end{array}$} & L1 & 16,69 aA & $14,60 \mathrm{aB}$ & $12,53 \mathrm{aC}$ & $9,00 \mathrm{aD}$ & $8,67 \mathrm{aD}$ \\
\hline & L2 & $15,03 \mathrm{cA}$ & $13,17 \mathrm{cB}$ & $11,10 \mathrm{cC}$ & 7,53 bcD & $7,20 \mathrm{bcD}$ \\
\hline & L3 & $16,05 \mathrm{aA}$ & $14,17 \mathrm{abB}$ & $12,07 a b c$ & $8,30 \mathrm{abD}$ & $7,97 \mathrm{abD}$ \\
\hline & L4 & $15,25 \mathrm{bcA}$ & $13,40 \mathrm{bcB}$ & $11,23 \mathrm{bcC}$ & $7,47 \mathrm{bcD}$ & $7,13 \mathrm{bcD}$ \\
\hline & L5 & $15,65 \mathrm{bcA}$ & $13,63 \mathrm{bcB}$ & $11,47 \mathrm{bcc}$ & 7,30 cD & $6,97 \mathrm{cD}$ \\
\hline \multirow{5}{*}{$\begin{array}{l}\text { Açúcares totais } \\
\left(\mathrm{g} 100 \mathrm{~mL}^{-1}\right)\end{array}$} & $\mathrm{L1}$ & $12,79 \mathrm{cD}$ & $14,29 \mathrm{cC}$ & $15,92 \mathrm{cB}$ & $15,78 \mathrm{eB}$ & $22,94 \mathrm{dA}$ \\
\hline & L2 & $12,63 \mathrm{cD}$ & $14,62 \mathrm{cC}$ & $15,87 \mathrm{cBC}$ & $17,21 \mathrm{~dB}$ & $23,84 \mathrm{dA}$ \\
\hline & L3 & $17,97 \mathrm{aD}$ & $20,11 \mathrm{aC}$ & $23,40 \mathrm{aB}$ & $21,31 \mathrm{bc}$ & $28,87 \mathrm{bA}$ \\
\hline & L4 & $17,61 \mathrm{aE}$ & $19,29 \mathrm{aD}$ & $22,36 \mathrm{aC}$ & $24,58 \mathrm{aB}$ & 32,06 aA \\
\hline & L5 & $15,47 \mathrm{bE}$ & $17,16 \mathrm{bD}$ & $20,96 \mathrm{bB}$ & $19,37 \mathrm{cC}$ & $26,34 \mathrm{cA}$ \\
\hline \multirow{5}{*}{$\begin{array}{l}\text { Sólidos solúveis totais } \\
\text { ('Brix) }\end{array}$} & L1 & $29,10 \mathrm{dC}$ & $29,20 \mathrm{dC}$ & $30,00 \mathrm{~dB}$ & $30,00 \mathrm{~dB}$ & $32,00 \mathrm{dA}$ \\
\hline & L2 & $29,40 \mathrm{dC}$ & $29,50 \mathrm{dC}$ & $30,00 \mathrm{~dB}$ & $30,00 \mathrm{~dB}$ & $31,67 \mathrm{dA}$ \\
\hline & L3 & $39,00 \mathrm{aC}$ & $39,10 \mathrm{aC}$ & $40,00 \mathrm{aB}$ & $40,00 a B$ & 42,17 aA \\
\hline & L4 & $38,00 \mathrm{bC}$ & $38,10 \mathrm{bC}$ & $39,00 \mathrm{bB}$ & $39,00 \mathrm{bB}$ & $40,17 \mathrm{bA}$ \\
\hline & L5 & $34,10 \mathrm{cD}$ & $35,10 \mathrm{cC}$ & $35,60 \mathrm{cB}$ & $35,50 \mathrm{cBC}$ & $36,83 \mathrm{cA}$ \\
\hline \multirow{5}{*}{$\begin{array}{l}\text { Atividade de água } \\
\qquad\left(\mathrm{a}_{\mathrm{w}}\right)\end{array}$} & L1 & $0,986 \mathrm{aA}$ & $0,981 \mathrm{aB}$ & $0,982 \mathrm{aAB}$ & $0,978 \mathrm{aB}$ & $0,968 \mathrm{aC}$ \\
\hline & L2 & 0,984 abA & $0,981 \mathrm{aA}$ & 0,975 bB & 0,973 bB & $0,956 \mathrm{cC}$ \\
\hline & L3 & $0,975 \mathrm{cA}$ & $0,966 \mathrm{bB}$ & $0,966 \mathrm{cB}$ & $0,965 \mathrm{cB}$ & $0,954 \mathrm{cC}$ \\
\hline & L4 & $0,970 \mathrm{dA}$ & $0,966 \mathrm{bA}$ & $0,960 \mathrm{~dB}$ & $0,959 \mathrm{~dB}$ & $0,945 \mathrm{dC}$ \\
\hline & L5 & $0,981 \mathrm{bA}$ & $0,979 \mathrm{aA}$ & $0,977 \mathrm{bA}$ & $0,971 \mathrm{bB}$ & $0,961 \mathrm{bC}$ \\
\hline \multirow{5}{*}{$\begin{array}{l}\text { Acidez total titulável } \\
\text { em ácido citrico } \\
(\%)\end{array}$} & L1 & $0,20 \mathrm{cC}$ & $0,22 \mathrm{cBC}$ & $0,33 \mathrm{~cd} A$ & $0,25 \mathrm{cB}$ & $0,19 \mathrm{cdC}$ \\
\hline & L2 & $0,25 a b C$ & $0,26 a b C$ & 0,38 bA & $0,31 \mathrm{bB}$ & $0,25 a b C$ \\
\hline & L3 & $0,20 \mathrm{cC}$ & $0,25 \mathrm{bcB}$ & $0,31 \mathrm{dA}$ & $0,28 \mathrm{bAB}$ & $0,18 \mathrm{dC}$ \\
\hline & L4 & $0,28 \mathrm{aC}$ & $0,29 \mathrm{aC}$ & $0,42 \mathrm{aA}$ & $0,38 \mathrm{aB}$ & $0,26 \mathrm{aC}$ \\
\hline & L5 & $0,24 b \mathrm{C}$ & $0,25 \mathrm{bcC}$ & $0,39 \mathrm{bA}$ & $0,35 \mathrm{aB}$ & $0,23 \mathrm{bcc}$ \\
\hline
\end{tabular}

Teor alcoólico: $\mathrm{MG}=11,34 \% \mathrm{v} / \mathrm{v} ; \mathrm{CV}=3,25 \%$; DMS para colunas = 0,85; DMS para linhas = 0,85; Açúcares totais: $\mathrm{MG}=19,71 \mathrm{~g} 100 \mathrm{~mL}^{-1} ; \mathrm{CV}=3,04 \%$; DMS para colunas $=1,38 ; \mathrm{DMS}$ para linhas = 1,38; Sólidos solúveis totais: $M G=19,71^{\circ}$ Brix; $C V=0,57 \%$; DMS para colunas = 0,46; DMS para linhas = 0,46; Atividade de água: $M G=0,970 ; C V=0,20 \%$; DMS para colunas = 0,005; DMS para linhas =0,005; Acidez total titulável: $M G=0,28 \%$; CV = 5,82\%; DMS para colunas =0,04; DMS para linhas $=0,04 ;$ L1 ... L5 - Licor de graviola; MG - Média geral; CV - Coeficiente de variação; DMS - Diferença mínimo significativo; Médias seguidas da mesma letra minúscula nas colunas e maiúscula nas linhas, não diferem estatisticamente pelo teste de Tukey, a 0,05 de probabilidade; análise estatística aplicada individualmente para cada parâmetro avaliado 
com graduações alcoólicas mais elevadas e a utilização de embalagens de vidros que constituem barreiras físicas mais eficientes. Ao final da estocagem, os teores alcoólicos variavam de 6,97 (L5) a $8,67 \% \mathrm{v} / \mathrm{v}$ (L1), estando próximos à faixa alcoólica (5,49 a 8,36\% v/v) reportada por Gómez et al. (2005) em licores de $R$. glaucus.

Os licores apresentaram, após processamento (tempo 0), teores de açúcares totais superiores a $3 \mathrm{~g} 100 \mathrm{~mL}^{-1}$, que é o mínimo estabelecido pela legislação brasileira vigente (Brasil, 2009), com valores oscilando entre 12,63 (L2) a $17,97{\mathrm{~g} 100 \mathrm{~mL}^{-1}}^{-1}$ (L3) (Tabela 2). Como se supunha, as maiores concentrações de açúcares totais foram encontradas nas bebidas elaboradas com xarope a $70^{\circ} \mathrm{Brix}$ (L3 e L4), diferindo estatisticamente $(\mathrm{p}<0,05)$ das demais formulações, o que está relacionado à elevada concentração de sólidos que este xarope apresentava em solução. Resultados superiores de açúcares totais foram relatados por Dias et al. (2011) em licor de maracujá-amarelo

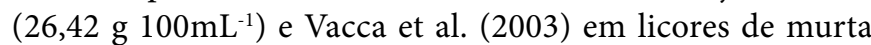

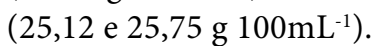

Observou-se que os açúcares totais aumentaram significativamente $(\mathrm{p}<0,05)$ durante o armazenamento dos licores (Tabela 2), atingindo teores compreendidos entre

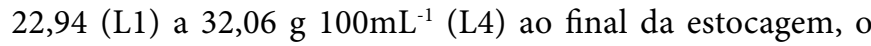
que também pode estar relacionado ao tipo de embalagem utilizada. Como, provavelmente, ocorreram trocas gasosas entre os licores e o ambiente, os sólidos dos licores, dentre eles os açúcares, foram concentrados ao passo que os solventes líquidos eram volatilizados. Considerando que a combinação adequada de açúcar e teor alcoólico desempenha papel fundamental na aceitação de licores (Barros et al., 2008) e que houve variações nesses parâmetros analíticos durante o armazenamento, torna-se imprescindível a investigação sensorial dessas bebidas durante a estocagem para se verificar o impacto das alterações nas proporções de açúcar e álcool registradas na aceitação sensorial.

No tempo inicial (tempo 0), os sólidos solúveis totais oscilaram de 29,10 (L1) a $39^{\circ} \mathrm{Brix}$ (L3) (Tabela 2), com os licores adicionados do xarope com $70^{\circ} \mathrm{Brix}$ (L3 e L4) apresentando os maiores valores, além de diferir estatisticamente $(\mathrm{p}<$ $0,05)$ das demais bebidas processadas. Referida variação é devida sobretudo aos xaropes utilizados com o objetivo de se aumentar os açúcares dos licores. Como a legislação (Brasil, 2009) permite extensa faixa de utilização de açúcar em licores de frutas, é comum a variação de sólidos solúveis totais nessas bebidas. Resultados semelhantes aos da faixa encontrada neste trabalho, foram reportados por Teixeira et al. (2012) e Vieira et al. (2010) ao processarem licores de abacaxi $\left(27,7\right.$ a $31^{\circ}$ Brix $)$ e camu-camu ( $\left.33^{\circ} \mathrm{Brix}\right)$, respectivamente enquanto valores superiores foram encontrados por Dias et al. (2011) em licores de maracujá-amarelo ( $\left.48^{\circ} \mathrm{Brix}\right)$.

Os sólidos solúveis totais aumentaram de maneira significativa $(\mathrm{p}<0,05)$ durante o armazenamento dos licores de graviola (Tabela 2), estando relacionado à concentração dos açúcares das bebidas em igual período. Ao final da estocagem as bebidas apresentaram mais de $30^{\circ} \mathrm{Brix}$, sendo que os licores formulados com xarope com $70^{\circ} \mathrm{Brix}$ revelaram concentração de sólidos solúveis totais superiores a $40^{\circ} \mathrm{Brix}$. Comportamento semelhante foi observado por Almeida et al. (2012) ao estocarem licores de casca de tangerina com diferentes concentrações do vegetal e tempos de maceração. Os autores citados reportaram que a bebida formulada com $500 \mathrm{~g}$ de cascas e macerada por 14 dias, teve aumento relevante dos sólidos solúveis totais, ao final dos 90 dias de armazenamento.

Verificaram-se, no tempo inicial, valores de atividade de água variando de 0,970 (L4) a 0,986 (L1), com apenas as bebidas formuladas com xarope a $70{ }^{\circ} \mathrm{Brix}$ (L3 e L4) apresentando valores inferiores a 0,980 (Tabela 2), além de diferir estatisticamente $(\mathrm{p}<0,05)$ entre os licores processados com xaropes a 50 e $60^{\circ} \mathrm{Brix}$. Apesar do álcool etílico presente nos licores inibir o desenvolvimento da maioria dos microorganismos de interesse em alimentos, os valores elevados de atividade de água sugerem que essas bebidas devem ser processadas com matérias-primas de boa qualidade sanitária e procedência conhecida, além de cumprimento das recomendações das boas práticas de fabricação durante o processo produtivo e aplicação de tratamento térmico eficiente.

Durante o armazenamento os valores de atividade de água decresceram significativamente $(\mathrm{p}<0,05)$ em todas as formulações de licores, o que pode ser atribuído à concentração dos açúcares. A maior proporção deste soluto em solução com o decorrer da estocagem, reduz a água livre dos licores, em virtude da formação de ligações intermoleculares entre a água e o açúcar diminuindo, deste modo, a atividade de água das bebidas. Ao final da estocagem os licores de graviola revelaram atividades de água compreendidas entre 0,940 (L4) e 0,968 (L1) (Tabela 2), com as bebidas formuladas com xarope a $70^{\circ} \mathrm{Brix}$ (L3 e L4) revelando os menores valores absolutos.

Quanto à acidez total titulável (Tabela 2), os licores de graviola apresentaram valores compreendidos entre 0,20 (L1 e L3) e $0,28 \%$ (L4) no tempo inicial (tempo 0), estando próximos aos resultados encontrados por Nogueira \& Venturini Filho (2005) ao analisarem licores de acerola (0,31 e 0,32\%) e superiores aos teores reportados por Gómez et al. (2005) ao caracterizarem licores de R. glaucus processados com diferentes concentrações de polpa $(0,94$ a $1,71 \%)$. As bebidas formuladas com as maiores concentrações de polpa (L2 e L4) revelaram os maiores teores de acidez diferindo estatisticamente ( $\mathrm{p}<$ $0,05)$ dos demais licores. Esses resultados estão relacionados principalmente à etapa de maceração das bebidas em que, além da extração de componentes aromáticos da polpa, também foram arrastados ácidos orgânicos. De acordo com Almeida et al. (2012), quanto menor a presença de ácidos em licores de frutas mais agradável e melhor será o produto ao paladar dos provadores; logo, as formulações L1 e L3, elaboradas com as menores concentrações de polpa, são as mais palatáveis, considerando-se este parâmetro.

Verificou-se, durante o armazenamento, que a acidez total titulável aumentou significativamente $(\mathrm{p}<0,05)$ em todos os licores até os 120 dias de estocagem, atingindo valores superiores a $0,30 \%$ em todas as formulações (Tabela 2), o que pode estar relacionado à concentração dos ácidos orgânicos promovida pelas trocas gasosas em igual período. A partir dos 180 dias de estocagem os licores apresentaram redução nos valores de acidez total titulável atingindo, ao final do período de armazenamento, teores variando de 0,18 (L3) a $0,26 \%$ (L4), sendo estatisticamente iguais aos registrados no tempo inicial (tempo 0) o que é passível de estar relacionado às reações de degradação de ácidos orgânicos ao reagirem 
com pigmentos (Cano \& Marin, 1992). Resultados similares foram reportados por Almeida et al. (2012) estocando licores de casca de tangerina, com acidez titulável estável ao final de 90 dias de armazenamento.

Os valores de "ratio" (sensação de doçura) foram superiores a 100 no tempo inicial (Tabela 3) em todos os licores, com a bebida L3, formulada com a menor concentração de polpa e com xarope com o maior teor de sólidos solúveis $\left(70^{\circ} \mathrm{Brix}\right)$, revelando a maior razão $(196,52)$ devido ao balanço favorável entre os sólidos solúveis totais 2 e acidez total titulável (Tabela 2). Este resultado indica que o licor L3 foi, no tempo inicial, considerado o mais doce do ponto de vista sensorial, diferindo estatisticamente $(\mathrm{p}<0,05)$ das demais formulações. Barros et al. (2008) encontraram valores da razão semelhantes em licores cremosos à base de leite (192,86 a 225), enquanto que Vieira et al. (2010), Oliveira \& Santos (2011) e Almeida et al. (2012) reportaram, para licores de camu-camu, açaí e cascas de tangerina, respectivamente, dados da razão superiores a 500 .

Verificou-se que os valores da razão dos licores de graviola decresceram significativamente $(\mathrm{p}<0,05)$ até os 120 dias de estocagem, atingindo valores inferiores a 100 na maioria das bebidas (Tabela 3) com exceção do licor L3, devido principalmente à elevação da acidez em igual período (Tabela 2). A partir dos 180 dias de armazenamento o "ratio" aumentou em todas as bebidas. Não é possível estimar o impacto das alterações da razão com o decorrer do armazenamento tornando-se necessária a aplicação de testes sensoriais com esta finalidade de vez que, de acordo com Teixeira et al. (2011), a preferência por um licor está relacionada às combinações entre a razão, o teor alcoólico e o sabor da fruta.
Os licores de graviola processados com a maior concentração de polpa ( $\mathrm{L} 2$ e L4) revelaram os menores valores de $\mathrm{pH}$, diferindo estatisticamente das demais formulações (Tabela 3). Tal resultado é devido à maior proporção de polpa/álcool que as formulações L2 e L4 possuíam (Tabela 1); logo, mais ácidos orgânicos estariam presentes na solução hidroalcóolica, o que acarreta valores de $\mathrm{pH}$ mais baixos ao final da maceração (Teixeira et al., 2012). Nogueira \& Venturini Filho (2005) observaram valores de pH de 3,59 e 3,80 em licores de acerola, estando próximo à faixa encontrada nos licores deste trabalho (3,74 a 3,90); já Vacca et al. (2003) e Oliveira \& Santos (2011) reportaram valores de $\mathrm{pH}$ superiores a 5,0 em licores de murta e açaí, respectivamente.

No decorrer do armazenamento foi registrado aumento significativo $(\mathrm{p}<0,05)$ no $\mathrm{pH}$ dos licores até os 60 dias de estocagem, seguindo de queda até os 240 dias de armazenamento (Tabela 3 ). Neste período os licores apresentaram os menores valores de $\mathrm{pH}(3,30$ a 3,70$)$, diferindo estatisticamente $(\mathrm{p}<0,05)$ dos valores encontrados no tempo inicial (tempo 0). Esses resultados corroboram com Almeida et al. (2012) que, ao elaborarem licores de cascas de tangerina, também verificaram redução significativa no $\mathrm{pH}$ da maioria das bebidas processadas durante a estocagem. Apesar do $\mathrm{pH}$ dos licores variar em função do tempo de armazenamento, verificou-se que este parâmetro permaneceu inferior a $4,5 \mathrm{em}$ todos os períodos de estocagem (Tabela 3 ), o que garante certa estabilidade microbiológica, mesmo com a redução gradual no teor alcoólico (Tabela 2). Segundo Franco \& Landgraf (2005), o baixo $\mathrm{pH}$ encontrado é importante por se tratar de um fator limitante para o crescimento de bactérias patogênicas

Tabela 3. Valores médios da razão, $\mathrm{pH}$, luminosidade e cromaticidades $\mathrm{a}^{*} \mathrm{e} \mathrm{b}^{*}$ de licores de graviola armazenados em condições ambientais

\begin{tabular}{|c|c|c|c|c|c|c|}
\hline \multirow{2}{*}{ Parâmetro } & \multirow{2}{*}{ Formulação } & \multicolumn{5}{|c|}{ Armazenamento (dias) } \\
\hline & & 0 & 60 & 120 & 180 & 240 \\
\hline \multirow{5}{*}{$\begin{array}{c}\text { Razão } \\
\text { (SST/ATT) }\end{array}$} & L1 & $147,81 \mathrm{bB}$ & $133,22 \mathrm{bBC}$ & $91,45 b D$ & $121,91 b C$ & $166,09 \mathrm{bA}$ \\
\hline & L2 & $118,44 \mathrm{CA}$ & $113,60 \mathrm{cA}$ & $79,78 \mathrm{bB}$ & $96,48 \mathrm{cB}$ & $128,69 \mathrm{cA}$ \\
\hline & L3 & $196,52 \mathrm{aB}$ & $157,49 \mathrm{aC}$ & $129,68 \mathrm{aD}$ & $142,41 \mathrm{aCD}$ & $229,24 \mathrm{aA}$ \\
\hline & L4 & $138,13 \mathrm{bAB}$ & $129,37 \mathrm{bcB}$ & $93,69 \mathrm{bc}$ & $103,82 \mathrm{cC}$ & $151,89 \mathrm{bA}$ \\
\hline & L5 & $143,51 \mathrm{bB}$ & $140,83 \mathrm{abB}$ & $90,13 \mathrm{bc}$ & $100,62 \mathrm{cC}$ & $162,45 \mathrm{bA}$ \\
\hline \multirow{5}{*}{$\mathrm{pH}$} & L1 & $3,90 \mathrm{aB}$ & $4,08 \mathrm{bA}$ & $3,91 \mathrm{aB}$ & $3,73 \mathrm{aC}$ & $3,70 \mathrm{aC}$ \\
\hline & L2 & $3,75 \mathrm{bC}$ & $4,05 \mathrm{bA}$ & $3,86 \mathrm{bB}$ & $3,51 \mathrm{bD}$ & 3,47 bD \\
\hline & L3 & $3,85 \mathrm{aC}$ & $4,15 \mathrm{aA}$ & $3,91 \mathrm{aB}$ & $3,54 \mathrm{bD}$ & $3,50 \mathrm{bD}$ \\
\hline & L4 & $3,74 \mathrm{bC}$ & $4,03 \mathrm{bA}$ & $3,82 \mathrm{bB}$ & $3,36 \mathrm{dD}$ & $3,30 \mathrm{dE}$ \\
\hline & L5 & $3,85 \mathrm{aB}$ & $4,04 \mathrm{bA}$ & $3,87 \mathrm{abB}$ & $3,43 \mathrm{cC}$ & $3,40 \mathrm{cC}$ \\
\hline \multirow{5}{*}{$\begin{array}{l}\text { Luminosidade } \\
\qquad\left(\mathrm{L}^{\star}\right)\end{array}$} & L1 & $61,27 \mathrm{aA}$ & $45,50 \mathrm{aB}$ & $44,42 \mathrm{abB}$ & $44,22 \mathrm{aB}$ & $43,94 \mathrm{aB}$ \\
\hline & L2 & $58,57 \mathrm{aA}$ & $46,42 \mathrm{aB}$ & 45,31 aB & $44,21 \mathrm{aB}$ & $43,70 \mathrm{aB}$ \\
\hline & L3 & $60,89 \mathrm{aA}$ & $44,02 \mathrm{aB}$ & $42,24 \mathrm{bBC}$ & $42,39 \mathrm{aBC}$ & $39,89 \mathrm{bC}$ \\
\hline & L4 & $55,71 \mathrm{bA}$ & $46,08 \mathrm{aB}$ & $45,74 \mathrm{aB}$ & $42,14 \mathrm{aC}$ & $43,59 \mathrm{aBC}$ \\
\hline & L5 & $60,91 \mathrm{aA}$ & $46,08 \mathrm{aB}$ & $44,73 \mathrm{abB}$ & $43,54 \mathrm{aB}$ & $43,53 \mathrm{aB}$ \\
\hline \multirow{5}{*}{ Cromaticidade $\mathrm{a}^{*}$} & L1 & $1,07 \mathrm{abB}$ & $-0,99 \mathrm{bE}$ & $-0,25 b D$ & $0,39 \mathrm{bC}$ & $1,65 \mathrm{cA}$ \\
\hline & L2 & $1,22 \mathrm{aB}$ & $-0,31 \mathrm{aC}$ & $-0,27 b C$ & $-0,13 \mathrm{dC}$ & $2,86 \mathrm{aA}$ \\
\hline & L3 & $1,07 a b A$ & $-1,39 \mathrm{cdC}$ & $-1,47 \mathrm{dC}$ & $-0,67 \mathrm{eB}$ & $1,11 \mathrm{dA}$ \\
\hline & L4 & $0,66 \mathrm{cB}$ & $-1,37 \mathrm{cD}$ & $0,03 \mathrm{aC}$ & $0,80 \mathrm{aB}$ & $2,60 \mathrm{bA}$ \\
\hline & L5 & $0,88 \mathrm{bB}$ & $-1,59 \mathrm{dE}$ & $-0,42 c D$ & $0,15 \mathrm{cC}$ & $2,44 \mathrm{bA}$ \\
\hline \multirow{5}{*}{ Cromaticidade $b^{\star}$} & $\mathrm{L} 1$ & $10,64 \mathrm{cB}$ & $4,31 \mathrm{cC}$ & $4,71 \mathrm{dC}$ & $10,33 \mathrm{bB}$ & $11,81 \mathrm{cA}$ \\
\hline & L2 & $12,31 \mathrm{bB}$ & $6,33 \mathrm{abE}$ & $8.62 \mathrm{aD}$ & $10,20 \mathrm{bC}$ & $15.61 \mathrm{bA}$ \\
\hline & L3 & $11,65 \mathrm{bA}$ & $4,25 \mathrm{cD}$ & $5,22 \mathrm{dC}$ & $8,34 \mathrm{~dB}$ & $11,51 \mathrm{cA}$ \\
\hline & L4 & $14,61 \mathrm{aB}$ & $6,48 \mathrm{aD}$ & $7,74 \mathrm{bC}$ & $14,45 \mathrm{aB}$ & $18,42 \mathrm{aA}$ \\
\hline & L5 & $12,13 \mathrm{bB}$ & $6,08 \mathrm{bE}$ & $7,33 b \mathrm{~b}$ & $9,19 \mathrm{cC}$ & $15,72 b \mathrm{~A}$ \\
\hline
\end{tabular}

Razão: $M G=132,29 ;$ CV = 5,56\%; DMS para colunas = 16,96; DMS para linhas $=16,96 ; \mathrm{pH}$ : MG = 3,75; CV = 0,54\%; DMS para colunas = 0,05; DMS para linhas $=0,05 ;$ Luminosidade: $M G=47,17 ; \mathrm{CV}=2,51 \%$; DMS para colunas $=2,74 ;$ DMS para linhas $=2,74 ;$ Cromaticidade $a^{*}:$ MG $=0,32 ; C V=3,98 \% ;$ DMS para colunas $=0,21 ;$ DMS para linhas $=0,21 ;$ Cromaticidade b*: MG = 9,92; CV = 3,06\%; DMS para colunas = 0,70; DMS para linhas = 0,70; L1... L5 - Licor de graviola; MG - Média geral; CV - Coeficiente de variação; DMS - Diferença mínimo significativo; Médias seguidas da mesma letra minúscula nas colunas e maiúscula nas linhas, não diferem estatisticamente pelo teste de Tukey, a 5\% de significância; análise estatística aplicada individualmente para cada parâmetro avaliado 
e deterioradoras, além de favorecer a estabilidade de ácido ascórbico, uma vez que esta vitamina tem maior estabilidade em $\mathrm{pH}$ ácido.

Em relação à luminosidade $\left(\mathrm{L}^{\star}\right)$, os licores de graviola se mantiveram claros após o processamento (tempo 0 ), com $\mathrm{L}^{\star}$ variando de 55,71 (L3) a 61,27 (L1) (Tabela 3). A bebida formulada com a maior concentração de polpa e xarope com sólidos solúveis totais de $70^{\circ} \mathrm{Brix}$ (L4) foi a que apresentou a menor claridade diferindo estatisticamente de todos os outros licores em razão, provavelmente, do escurecimento enzimático ocasionado pela maior proporção de polpa, somados à contribuição do xarope, que apresentou coloração levemente acastanhada, uma vez que foi o mais concentrado. Shen et al. (2007) encontraram valores de $L^{*}$ semelhantes ao elaborarem licor de Rosa hybrida (59,13 a 64,22); já Teixeira et al. (2005) reportaram, em licores de banana, $\mathrm{L}^{*}$ superior 80 .

$\mathrm{A} \mathrm{L}^{*}$ dos licores decresceu significativamente $(\mathrm{p}<0,05)$ durante $\mathrm{o}$ armazenamento atingindo valores inferiores a 44,00 em todas as formulações (Tabela 3 ) indicando suscetibilidade dessas bebidas ao escurecimento (Oliveira et al., 2012). Isto é devido, provavelmente, à síntese de compostos escuros através da reação de Maillard. Como a graviola apresenta quantidade considerável de proteínas em sua composição (Okigbo \& Obire, 2009), os aminoácidos livres provenientes da polpa podem reagir com açúcares redutores sintetizando as melanoidinas. Como os licores devem apresentar as características sensoriais da fruta (cor, sabor e aroma), o escurecimento dos licores de graviola pode favorecer a rejeição visto que, de origem, a fruta é clara. Uma alternativa para desacelerar este escurecimento seria o armazenamento das bebidas sob refrigeração; contudo, pode haver precipitação de açúcares, além de aumento de custos para manter o frio.

A cromaticidade $\mathrm{a}^{*}$ apresentou resultados positivos após processamento (tempo 0 ), com valores compreendidos entre 0,66 (L4) e 1,22 (L2) (Tabela 3), indicando que os licores tiveram leve tonalidade avermelhada. Resultados similares também foram encontrados por Teixeira et al. (2005) ao processarem licores de banana, com cromaticidades $a^{\star}$ variando de 1,30 a 2,42. Durante o armazenamento os valores de cromaticidade $\mathrm{a}^{\star}$ reduziram significativamente $(\mathrm{p}<0,05)$ até os 60 dias de estocagem em todas as bebidas, com exceção das amostras L3, que tiveram a cromaticidade $\mathrm{a}^{\star}$ reduzida até os 120 dias de armazenamento. Posteriormente, todos os licores apresentaram aumento gradual nas cromaticidade $\mathrm{a}^{*}$ até os 240 dias de armazenamento (Tabela 3 ). Ao final da estocagem as formulações apresentavam cromaticidades $\mathrm{a}^{\star}$ oscilando entre 1,11 (L3) e 2,86 (L2), diferindo estatisticamente dos valores encontrados nos demais pontos de armazenamento.

No tempo inicial os valores de cromaticidade $b^{*}$ variaram de 10,64 (L1) a 14,61 (L4) (Tabela 3) sinalizando tonalidade amarela suave. O licor L4, processado com a maior concentração de polpa e xarope com sólidos solúveis totais de $70^{\circ} \mathrm{Brix}$, foi o que teve a intensidade de amarelo mais perceptível diferindo estatisticamente $(\mathrm{p}<0,05)$ das demais bebidas. Teixeira et al. (2005) reportaram, em licores de banana, valores de cromaticidade $b^{*}$ próximos aos deste trabalho, com uma variação de 9,23 a 15,00. Quanto ao armazenamento, os dados de cromaticidade $b^{*}$ dos licores foram reduzidos até os 60 dias de estocagem sendo posteriormente verificados acréscimos graduais até os 240 dias de armazenamento. Ao final deste período a cromaticidade $b^{*}$ se apresentava 11,00 , com a maioria das bebidas diferindo estatisticamente dos dados iniciais.

O processamento dos frutos da gravioleira para produção de licor é mais uma alternativa de agregação de valor à espécie, com possibilidades de aproveitamento do excedente de produção durante a safra, além de disponibilizar os produtos da graviola a locais mais distantes das regiões produtoras e se constituir em fonte de renda para pequenos produtores.

\section{Conclusões}

1. O armazenamento de licores de graviola acondicionados em embalagens de polietileno de baixa densidade promoveu, ao final da estocagem, aumentos significativos nos valores de açúcares totais, sólidos solúveis totais e cromaticidades $\mathrm{a}^{*} \mathrm{e} \mathrm{b}^{*}$.

2. Os parâmetros teor alcoólico, atividade de água, $\mathrm{pH}$ e luminosidade $\left(L^{*}\right)$ foram reduzidos significativamente enquanto a acidez total titulável e o "ratio" permaneceram estatisticamente estáveis ao final do armazenamento.

\section{Literatura Citada}

Almeida, E. L.; Lima, L. C.; Borges, V. T. N.; Martins, R. N.; Batalini, C. Elaboração de licor de casca de tangerina. Alimentos e Nutrição, v.23, p.259-265, 2012.

AOAC - Association of Official Analytical Chemists. Official Methods of Analysis. 3.ed. Review, Washington: AOAC, 2010. 1094p.

Barros, J. C.; Santos, P. A.; Isepon, J. S.; Silva, J. W.; Silva, M. A. P. Obtenção e avaliação de licor de leite a partir de diferentes fontes alcoólicas. Global Science and Technology, v.1, p.27-33, 2008.

Brasil. Ministério da Agricultura, Pecuária e Abastecimento. Portaria $\mathrm{n}^{\circ}$ 76, de 27 de novembro 1986. Diário Oficial da União, Brasília: MAPA, 1986. p.18152-18173.

Brasil. Ministério da Agricultura, Pecuária e Abastecimento. Decreto n. 6871, de 4 de junho de 2009. Regulamenta a lei n. 8.918 de 14 de julho de 1994. Dispõe sobre a padronização, a classificação, o registro, a inspeção, a produção e a fiscalização de bebidas. Diário Oficial da União, Brasília: MAPA 2009. p.10661.

Cano, M. P.; Marín, M. A. Pigment composition and colour of frozen and canned kiwi fruit slices. Journal Agricultural Food Chemistry, v.40, p.2141-2146, 1992. http://dx.doi.org/10.1021/jf00023a020

Carvalho, R. F. Produção de licores. Dossiê técnico. Rede de Tecnologia da Bahia: RETEC/BA, 2007. 27p.

Dias, S. C.; Cardoso, R. L.; Batista, D. V. S.; Santos, D. B.; Assis, S. S. Caracterização físico-química e sensorial do licor de corte do maracujá amarelo. Enciclopédia Biosfera, v.7, p.1405-1412, 2011.

Franco, B. D. G. M.; Landgraf, M. Microbiologia dos alimentos. 1.ed. São Paulo: Atheneu, 2005. 196p.

Gómez, A. M.; Gómez, J. K. L.; Cardozo, C. J. M. Licor de mora de castilla (Rubus glaucus Benth) con diferentes porcentajes de pulpa. Revista Facultad Nacional de Agronomia, v.58, p.2963-2973, 2005.

IAL - Instituto Adolfo Lutz. Normas analíticas, métodos químicos e físicos para análises de alimentos. 1.ed. Digital, São Paulo: IAL, 2008. 1020p.

Lima, M. A. C.; Alves, R. E.; Filgueiras, H. A. C. Mudanças relacionadas ao amaciamento da graviola durante a maturação pós-colheita. Pesquisa Agropecuária Brasileira, v.41, p.1707-1713, 2006. http:// dx.doi.org/10.1590/S0100-204X2006001200004 
Lima, M. A. C.; Alves, R. E.; Filgueiras, H. A. C. Comportamento respiratório e amaciamento de graviola (Annona muricata L.) após tratamentos pós-colheita com cera e 1-metilciclopropeno. Ciência e Agrotecnologia, v.34, p.155-162, 2010. http://dx.doi. org/10.1590/S1413-70542010000100020

Nogueira, A. M. P.; Venturini Filho, W. G. Ultra e microfiltração de licor de acerola. Brazilian Journal of Food Technology, v.8, p.305-311, 2005.

Okigbo, R. N.; Obire, O. Mycoflora and production of wine from fruits of soursop (Annona Muricata L.). International Journal of Wine Research, v.1, p.1-9, 2009.

Oliveira, E. N. A. de; Martins, J. N.; Santos, D. C.; Gomes, J. P.; Almeida, F. de A. C. Armazenamento de tomates revestidos com pectina: Avaliação colorimétrica. Revista Caatinga, v.25, p.19-25, 2012.

Oliveira, E. N. A. de; Santos, D. C. Processamento e avaliação da qualidade de licor de açaí (Euterpe oleracea Mart.). Revista do Instituto Adolfo Lutz, v.70, p.534-41, 2011.

Oliveira, E. N. A. de; Santos, D. C.; Santos, Y. M. G.; Oliveira, F. A. A. Aproveitamento agroindustrial da graviola (Annona muricata L.) para produção de licores: Avaliação sensorial. Journal of Biotechnology and Biodiversity, v.5, p.33-42, 2014.

Shen, S. C.; Tseng, K. C.; Chao, F. T.; Wu, J. S. B. Color quality of rose liqueur. Journal of Food Quality, v.30, p.202-217, 2007. http:// dx.doi.org/10.1111/j.1745-4557.2007.00115.x
Silva, F. de A. S. e; Azevedo, C. A. V. de. Assistat - Programa estatístico, versão 7.5 (Beta), Campina Grande, Paraíba, 2008.

Teixeira, L. J. Q.; Ramos, A. M.; Chaves, J. B. P.; Silva, P. H. A.; Stringheta, P. C. Avaliação tecnológica da extração alcoólica no processamento de licor de banana. Boletim do Centro de Pesquisa de Processamento de Alimentos, v.23, p.329-346, 2005.

Teixeira, L. J. Q.; Rocha, C. T.; Junqueira, M. S.; Saraiva, S. H. Determinação da cinética de extração alcoólica no processamento de licor de café. Enciclopédia Biosfera, v.6, p.1-9. 2010.

Teixeira, L. J. Q.; Simões, L. S.; Rocha, C. T.; Saraiva, S. H.; Junqueira, M. S. Tecnologia, composição e processamento de licores. Enciclopédia Biosfera, v.7, p.1-17, 2011.

Teixeira, L. J. Q.; Simões, L. S.; Saraiva, S. H.; Junqueira, M. S.; Sartori, M. A. Determinação da proporção de açúcar e fruta necessários para conferir os atributos ideiais ao licor de abacaxi. Enciclopédia Biosfera, v.8, p.1883-1889, 2012.

Vacca, V.; Piga, A.; Caro, A.; Fenu, P. A. M.; Agabbio, M. Changes in phenolic compounds, colour and antioxidant activity in industrial red myrtle liqueurs during storage. Nahrung/Food, v.47, p.442447, 2003.

Vieira, V. B.; Rodrigues, J. B.; Brasil, C. C. B.; Rosa, C. S. Produção, caracterização e aceitabilidade de licor de camu-camu (Myrciaria dubia (H.B.K.) McVaugh). Alimentos e Nutrição, v.21, p.519-522, 2010. 